\title{
The Activity of $\sigma^{\mathrm{V}}$, an Extracytoplasmic Function $\sigma$ Factor of Bacillus subtilis, Is Controlled by Regulated Proteolysis of the Anti- $\sigma$ Factor RsiV
}

\author{
Jessica L. Hastie, Kyle B. Williams, Craig D. Ellermeier \\ Department of Microbiology, Carver College of Medicine, University of lowa, lowa City, lowa, USA
}

During growth in the environment, bacteria encounter stresses which can delay or inhibit their growth. To defend against these stresses, bacteria induce both resistance and repair mechanisms. Many bacteria regulate these resistance mechanisms using a group of alternative $\sigma$ factors called extracytoplasmic function (ECF) $\sigma$ factors. ECF $\sigma$ factors represent the largest and most diverse family of $\sigma$ factors. Here, we demonstrate that the activation of a member of the ECF30 subfamily of ECF $\sigma$ factors, $\sigma^{\mathrm{V}}$ in Bacillus subtilis, is controlled by the proteolytic destruction of the anti-o factor RsiV. We will demonstrate that the degradation of RsiV and, thus, the activation of $\sigma^{\mathrm{V}}$ requires multiple proteolytic steps. Upon exposure to the inducer lysozyme, the extracellular domain of RsiV is removed by an unknown protease, which cleaves at site 1 . This cleavage is independent of PrsW, the $B$. subtilis site 1 protease, which cleaves the anti-o factor RsiW. Following cleavage by the unknown protease, the N-terminal portion of RsiV requires further processing, which requires the site 2 intramembrane protease RasP. Our data indicate that the $\mathrm{N}$ terminal portion of RsiV from amino acid 1 to 60 , which lacks the extracellular domain, is constitutively degraded unless RasP is absent, indicating that RasP cleavage is constitutive. This suggests that the regulatory step in RsiV degradation and, thus, $\sigma^{\mathrm{V}}$ activation are controlled at the level of the site 1 cleavage. Finally, we provide evidence that increased resistance to lysozyme decreases $\sigma^{\mathrm{V}}$ activation. Collectively, these data provide evidence that the mechanism for $\sigma^{\mathrm{V}}$ activation in $B$. subtilis is controlled by regulated intramembrane proteolysis (RIP) and requires the site 2 protease RasP.

$S^{\mathrm{tr}} \mathrm{sin}$ tress response systems are important for bacteria to adapt and survive in changing environments. Extracytoplasmic function (ECF) $\sigma$ factors are alternative $\sigma$ factors that interact with RNA polymerase and transcribe sets of genes required for environmental adaption in response to specific signal(s) (1). Most known ECF $\sigma$ factors are held in an inactive state during normal growth conditions by an anti- $\sigma$ factor that prevents the ECF $\sigma$ factor from interacting with RNA polymerase $(1,2)$. Exposure to specific cell envelope stresses induces a proteolytic cascade termed regulated intramembrane proteolysis (RIP), which results in the destruction of a membrane-tethered anti- $\sigma$ factor $(3,4)$. Upon sensing cell envelope stress, a protease cleaves the anti- $\sigma$ factor at site 1 in the extracellular domain of the anti- $\sigma$ factor (3). This is followed by a second cleavage (site 2 ) within the transmembrane domain of the anti- $\sigma$ factor (3). The remainder of the freed anti- $\sigma$ factor is degraded by cytosolic proteases, resulting in the release of free $\sigma$ factor, which is able to interact with RNA polymerase to transcribe the appropriate target genes (4).

The best-studied example of ECF $\sigma$ factor activation is that of Escherichia coli $\sigma^{\mathrm{E}}$. Normally, $\sigma^{\mathrm{E}}$ is held inactive by the membrane-bound anti- $\sigma$ factor RseA, which sequesters $\sigma^{\mathrm{E}}$ to the cytoplasmic membrane. In response to cell envelope stress, in this case unfolded outer membrane $\beta$-barrel proteins, RseA is cleaved by the protease DegS at site 1 (see Fig. S1 in the supplemental material) (5-8). The RseA site 1 cleavage product becomes a substrate for RseP, a site 2 protease (9-11). RseP then clips RseA within the transmembrane domain, releasing the $\mathrm{N}$-terminal portion of RseA to the cytosol where it can be further degraded by multiple cytosolic proteases (12). This proteolytic cascade leads to the destruction of the anti- $\sigma$ factor RseA and results in free $\sigma^{\mathrm{E}}$, which can transcribe genes required to respond to cell envelope stress (13).
Bacillus subtilis encodes seven ECF $\sigma$ factors (14). Of those ECF $\sigma$ factors, only the mechanism of $\sigma^{\mathrm{W}}$ activation has been well characterized. The activity of $\sigma^{\mathrm{W}}$ is induced by a variety of cell envelope stresses, including salt stress, $\mathrm{pH}$ stress (base stress), and antimicrobial peptides $(15,16)$. The regulation of $\sigma^{\mathrm{W}}$ activity is similar to but distinct from the regulation of $\sigma^{\mathrm{E}}$ activity in $E$. coli $(4,9,17-19)$. In response to cell envelope stress, PrsW, a type II CAAX prenyl endopeptidase, cleaves the extracellular domain of the anti- $\sigma$ factor RsiW at site 1 (see Fig. S1 in the supplemental material) $(18,19)$. A second, as-yet-unidentified protease further trims the extracellular portion of RsiW (17). Following truncation of the extracellular domain of RsiW by PrsW and the unknown protease(s), RsiW is cleaved by the site 2 metalloprotease RasP (17). The activation of $\sigma^{\mathrm{W}}$ requires degradation of the released $\sigma$ factor binding domain of RsiW by the cytosolic proteases ClpXP (20). While PrsW is structurally unrelated to DegS, the E. coli site 1 protease, RasP shares homology to the E. coli site 2 protease RseP. In both regulatory systems, it has been shown that site 1 cleavage is required before site 2 cleavage can occur $(17,21)$.

Site 2 proteases are thought to have an ancient origin and can be found in the genome sequences of archaea, bacteria, and eukaryotes (22). Although there is great substrate diversity, site 2

Received 13 March 2013 Accepted 14 May 2013

Published ahead of print 17 May 2013

Address correspondence to Craig D. Ellermeier, craig-ellermeier@uiowa.edu.

Supplemental material for this article may be found at http://dx.doi.org/10.1128 /JB.00292-13

Copyright @ 2013, American Society for Microbiology. All Rights Reserved. doi:10.1128/JB.00292-13 
proteases cleave within the transmembrane helices of proteins which contain helix-destabilizing residues (22). In Mycobacterium tuberculosis, it has been shown that a site 2 protease homolog, Rv2869c (Rip1), is required for the cleavage of three different anti- $\sigma$ factors, each of which inhibits the activity of a different ECF $\sigma$ factor (23). In humans, the site 2 protease, S2P, has four different substrates, some of which regulate cholesterol biosynthesis and the endoplasmic reticulum stress response $(24,25)$. In B. subtilis, the site 2 protease RasP is known to cleave the cell division protein FtsL, in addition to the $\sigma^{\mathrm{W}}$ anti- $\sigma$ factor RsiW (26). Recent evidence suggests that site 2 proteases, including RasP, are required for clearing signal peptides from the membrane (27). Here, we identify another substrate for RasP in B. subtilis, namely, the anti- $\sigma$ factor RsiV, which inhibits $\sigma^{\mathrm{V}}$ activity.

$\sigma^{\mathrm{V}}$ belongs to a unique subfamily of ECF $\sigma$ factors (ECF30) which are primarily found in the firmicutes (low-GC, Gram-positive bacteria) (2). In $B$. subtilis, $\sigma^{\mathrm{V}}$ is encoded with three other genes, $r s i V$ (the anti- $\sigma$ factor), oat $A$ ( $O$-acetyltransferase), and yrhK (unknown function) $(28,29)$. We previously found that the activity of $B$. subtilis $\sigma^{\mathrm{V}}$ was induced by lysozyme (28). Lysozyme is an important component of the innate immune system which cleaves the peptidoglycan of bacteria between the $\beta$ - $(1,4)$-linked $N$-acetylglucosamine and $N$-acetylmuramic acid residues (30). The activation of $\sigma^{\mathrm{V}}$ induces the expression of oat $A(28,31)$. OatA increases lysozyme resistance, likely by transferring an acetyl group to the C-6-OH position of $\mathrm{N}$-acetylmuramic acid and thereby blocking lysozyme cleavage $(28,31-33)$.

Homologs of the $\sigma^{\mathrm{V}}$ system have been identified in Enterococcus faecalis and Clostridium difficile, where they are also induced in response to lysozyme (34-36). In E. faecalis, it has been demonstrated that $\sigma^{\mathrm{V}}$ is required for resistance to lysozyme and is important for virulence in mouse models of systemic and urinary tract infection (35). It is clear that in all of these cases, $\sigma^{\mathrm{V}}$ activity is inhibited by a single-pass transmembrane protein, $\operatorname{RsiV}(29,34$, 36). However, little is known about the mechanisms controlling the activation of $\sigma^{\mathrm{V}}$ in any organism. Here, we present evidence that the $\sigma^{\mathrm{V}}$ anti- $\sigma$ factor RsiV is degraded in a RIP-dependent manner in response to subinhibitory concentrations of lysozyme. Furthermore, our results show that RsiV degradation is independent of the RsiW site 1 protease PrsW. In contrast, the site 2 protease RasP is required for RsiV degradation once site 1 cleavage has occurred. Using truncated forms of RsiV, we also demonstrate that RasP constitutively degrades the site 1 cleavage product.

\section{MATERIALS AND METHODS}

Strain construction. All of B. subtilis strains used are isogenic derivatives of PY79, a prototrophic derivative of B. subtilis strain 168 (37). All cloning plasmids were constructed in the E. coli cloning strain Omnimax-2 (Invitrogen). Protein purification was done using E. coli BL21入DE3. Strain genotypes and plasmid descriptions are listed in Table 1. B. subtilis strains were constructed by transformation using competent cells prepared by the one-step method as previously described (38). All DNA oligomers were synthesized by IDT (Coralville, IA) and are listed in Table S1 in the supplemental material. The sequences of all plasmid constructs were confirmed by DNA sequencing (Iowa State University).

Native $r s i V^{+}$with an optimized ribosome binding site was PCR amplified from B. subtilis using oligonucleotides CDEP1430 and CDEP952 and cloned into pENTR/D-TOPO (Invitrogen), resulting in pCE351. For isopropyl- $\beta$-D-thiogalactopyranoside (IPTG)-inducible expression, the $r s i V^{+}$gene was moved into pCE292 (34) using LR Clonase II (Invitrogen). The resulting plasmid, pJH158, places the IPTG-inducible hyperspac pro- moter $\left(\mathrm{P}_{h s}\right)$ upstream from $r s i V^{+}$. An IPTG-inducible $p d a C^{+}$was constructed similarly, by PCR amplifying $p d a C$ from B. subtilis using oligonucleotides CDEP1245 and CDEP1246. The PCR product was cloned into pENTR/D-TOPO, resulting in pJH107, and moved into pCE292 with LR Clonase II, resulting in pJH166.

The rasP complementation plasmid was constructed by PCR amplifying ras $P$ from $B$. subtilis using oligonucleotides CDEP568 and CDEP569. The PCR product was digested with SalI and SphI and cloned into pDR111 digested with SalI and SphI, resulting in pCE170. In this construct, the expression of $\operatorname{ras} P^{+}$is IPTG inducible; however, the basal levels of expression were sufficient to complement a rasP null mutant (data not shown).

We constructed a derivative of pDR111, pCE235, in which the EcoRI and BamHI sites had been sequentially destroyed by digestion with the appropriate enzyme, blunt ended with the Klenow fragment, and religated. The $\mathrm{P}_{h s}$-green fluorescent protein (GFP) vector was constructed by PCR amplifying superfolder $g f p$ from pCM29 (39) using oligonucleotides CDEP615 and CDEP618. The resulting PCR product was digested with SalI and SphI and cloned into pDR111, which had been digested with HindIII and NheI, resulting in pCE236. A Gateway destination vector was constructed to build N-terminal $g f p-r s i V$ fusions (Invitrogen). This was generated by cloning the RfA cassette (Invitrogen) into pCE236, which had been digested with SphI and EcoRI and blunt ended with the Klenow fragment to generate pJH183. N-terminally GFP-tagged RsiV ${ }^{+}$(GFP$\mathrm{RsiV}^{+}$) was constructed by PCR amplifying rsiV from B. subtilis using oligonucleotides CDEP1460 and CDEP952 and cloning it into pENTR/DTOPO, resulting in pCE351. To construct a plasmid producing GFP$\mathrm{RsiV}^{+}, r s i V^{+}$was moved from pCE352 onto pJH183 using LR Clonase II (Invitrogen), resulting in plasmid pJH181. The GFP-RsiV ${ }^{1-60}$ vector was generated by PCR amplifying the portion of $r s i V$ that encodes the N-terminal amino acids 1 to $60\left(r s i V^{1-60}\right)$ from B. subtilis using CDEP1460 and CDEP978 and cloning the product into pENTR/D-TOPO, resulting in pJH198. To construct the plasmid producing GFP-RsiV ${ }^{1-60}, r s i V^{1-60}$ was moved from pJH198 onto pJH183 using LR Clonase II (Invitrogen), resulting in plasmid pJH204.

To generate antibodies to the extracellular domain of RsiV, the portion of $r s i V$ encoding the C-terminal extracellular domain (codons 59 to $285\left[\right.$ rsi $\left.^{59}{ }^{285}\right]$ ) was PCR amplified using CDEP1007 and CDEP952 and cloned into pENTR/D-TOPO, resulting in pCE458. To construct the recombinant $6 \times$ His-RsiV ${ }^{59-285}, r s i V^{59-285}$ from pCE458 was moved into the T7-inducible $6 \times$ His destination vector, pDEST17 (Invitrogen), using LR Clonase II, resulting in pKBW202.

Long flanking homology PCR was used to create $\Delta$ rasP::tet as previously described (40). The ras $P 5^{\prime}$ flanking region was PCR amplified using CDEP209 and CDEP1575. The rasP 3 ' flanking region was PCR amplified using CDEP1576 and CDEP212. The resulting PCR products were used as primers to amplify the tet cassette from pDG1515 (41). The resulting PCR product was directly transformed into PY79, resulting in strain JLH632.

Bacterial growth conditions. All E. coli and B. subtilis strains were grown in LB broth or on LB agar. Antibiotics were used at the following concentrations for B. subtilis: chloramphenicol, $5 \mu \mathrm{g} / \mathrm{ml}$; erythromycin plus lincomycin (MLS), $1 \mu \mathrm{g} / \mathrm{ml}$ and $25 \mu \mathrm{g} / \mathrm{ml}$, respectively; kanamycin, 5 $\mu \mathrm{g} / \mathrm{ml}$; spectinomycin, $100 \mu \mathrm{g} / \mathrm{ml}$; and tetracycline, $10 \mu \mathrm{g} / \mathrm{ml}$. The $\beta$ galactosidase chromogenic indicator 5-bromo-4-chloro-3-indolyl $\beta$-Dgalactopyranoside (X-Gal; RPI) was used at a concentration of $100 \mu \mathrm{g} / \mathrm{ml}$. Isopropyl $\beta$-D-1-thiogalactopyranoside (IPTG; RPI) was used at a final concentration of $1 \mathrm{mM}$ unless otherwise noted. Antibiotics were used at the following concentrations for E. coli: ampicillin, $100 \mu \mathrm{g} / \mathrm{ml}$; chloramphenicol, $10 \mu \mathrm{g} / \mathrm{ml}$; and kanamycin, $50 \mu \mathrm{g} / \mathrm{ml}$.

$\boldsymbol{\beta}$-Galactosidase activity assays. Cultures were grown overnight in LB broth at $30^{\circ} \mathrm{C}$, and $20-\mu \mathrm{l}$ amounts were spotted in triplicate onto LB agar. The plates were incubated at $37^{\circ} \mathrm{C}$ for $6 \mathrm{~h}$. Samples were harvested from the plates and resuspended in $500 \mu \mathrm{l}$ of $\mathrm{Z}$ buffer $\left(60 \mathrm{mM} \mathrm{Na}_{2} \mathrm{HPO}_{4}, 40\right.$ $\mathrm{mM} \mathrm{NaH}{ }_{2} \mathrm{PO}_{4}, 10 \mathrm{mM} \mathrm{KCl}, 1 \mathrm{mM} \mathrm{MgSO}{ }_{4}, 50 \mathrm{mM} \beta$-mercaptoethanol, $\mathrm{pH}$ 7.0). Resuspended cells $(250 \mu \mathrm{l})$ were transferred to a 96 -well plate, 
TABLE 1

\begin{tabular}{|c|c|c|}
\hline Strain or plasmid & Genotype $^{a}$ & Reference $^{b}$ \\
\hline \multicolumn{3}{|l|}{ Plasmids } \\
\hline pDR111 & $a m y E \mathrm{P}_{h s} \mathrm{Amp}^{\mathrm{r}} \mathrm{Spec}^{\mathrm{r}}$ & 56 \\
\hline pCE292 & pDR111 amyE $\mathrm{P}_{h s} \operatorname{Spec}^{\mathrm{r}} \operatorname{Amp}^{\mathrm{r}} \operatorname{Cam}^{\mathrm{r}} \mathrm{P}_{h s}-\mathrm{RfA}$ & 34 \\
\hline pJH158 & pCE292 amyE $\mathrm{P}_{h s}-r s i V^{+}$Spec $^{\mathrm{r}} \mathrm{Amp}^{\mathrm{r}}$ & \\
\hline pCE458 & pENTR/D-TOPO $r s i V^{59-285} \operatorname{Kan}^{\mathrm{r}}$ & \\
\hline pKBW202 & pDEST17 $\mathrm{P}_{\mathrm{T} 7}-6 \times$ His-rsi $V^{59-285} \mathrm{Amp}^{\mathrm{r}}$ & \\
\hline pJH183 & pCE235 amyE $\mathrm{P}_{h s}$-GFP-RfA Spec ${ }^{\mathrm{r}}$ Cam $^{\mathrm{r}} \mathrm{Amp}^{\mathrm{r}}$ & \\
\hline pJH198 & pENTR/D-TOPO $r s i V^{1-60} \operatorname{Kan}^{\mathrm{r}}$ & \\
\hline pJH204 & pJH183 amyE $\mathrm{P}_{h_{s}}-g f p-r s i V^{1-60} \operatorname{Spec}^{\mathrm{r}} A m p^{\mathrm{r}}$ & \\
\hline pJH101 & pENTR/D-TOPO oatA ${ }^{+} \operatorname{Kan}^{\mathrm{r}}$ & 28 \\
\hline pJH102 & pCE292 amyE $\mathrm{P}_{h s^{-}}$oatA $A^{+}$Spec $^{\mathrm{r}} \mathrm{Amp}^{\mathrm{r}}$ & 28 \\
\hline pJH107 & pENTR/D-TOPO $p d a C^{+} \operatorname{Kan}^{\mathrm{r}}$ & 44 \\
\hline \multicolumn{3}{|l|}{ Escherichia coli strains } \\
\hline Omnimax-2 T1R & $\begin{array}{l}\mathrm{F}^{\prime} \text { proAB }{ }^{+} \text {lac } I^{\mathrm{q}} \text { lacZ } \mathrm{M} 15 \mathrm{Tn} 10\left(\mathrm{Tet}^{\mathrm{r}}\right) \Delta c c d A B \text { mcrA } \Delta(\text { mrr-hsdRMS-mcrBC) } \phi 80 \text { lacZ } \mathrm{M} 15 \Delta(\text { lacZYA-argF }) \\
\mathrm{U} 169 \text { endA1 recA1 supE44 thi-1 gyrA96 relA1 tonA panD }\end{array}$ & \\
\hline BL21(DE3) & fhuA2 [lon] ompTgal( $\lambda \mathrm{DE} 3)[\mathrm{dcm}] \Delta h s d S(\lambda \mathrm{DE} 3)$ [sBamHIo $\Delta$ EcoRI-B int::(lacI::PlacUV5::T7 gene1) i21 $\Delta$ nin5] & \\
\hline \multicolumn{3}{|l|}{ Bacillus subtilis strains } \\
\hline PY79 & Prototrophic derivative of B. subtilis 168 & 37 \\
\hline CDE1546 & PY79 pyrD:: $\mathrm{P}_{\text {sigV }}$ lacZ (cat) & 28 \\
\hline CDE1563 & PY79 $\Delta($ sigV rsiV $):: k a n$ & \\
\hline CDE379 & PY79 $\Delta$ prsW::erm & 18 \\
\hline CDE1549 & PY79 pyrD:: $\mathrm{P}_{\text {sigV }}$-lacZ (cat) $\Delta$ prsW::erm & \\
\hline CDE1557 & 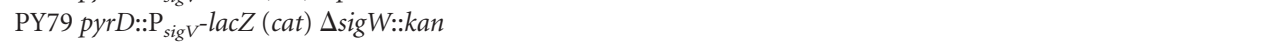 & \\
\hline JLH465 & PY79 amyE:: $\mathrm{P}_{h s}-g f p-r s i V^{+}($spec $) \Delta($ sigV rsiV)::kan $\Delta p r s W:: e r m$ & \\
\hline JLH467 & PY79 amyE:: $\mathrm{P}_{h s}-g f p-r s i V^{+}($spec $) \Delta($ sigV rsiV) $:: k a n \Delta p r s W:: e r m$ rasP::cat & \\
\hline JLH516 & PY79 amyE:: $\mathrm{P}_{h s}-g f p-r s i V^{1-60}($ spec $) \Delta($ sigV rsiV $):: k a n$ & \\
\hline JLH536 & PY79 amyE:: $\mathrm{P}_{h s}-g f p-r s i V^{1-60}($ spec $) \Delta($ sigV rsiV $):: k a n \Delta$ rasP::cat & \\
\hline TPM1263 & PY79 amyE:: $\mathrm{P}_{h s}-g f p($ spec $)$ & \\
\hline JLH345 & PY79 pryD:: $P_{\text {sigV }}$-lacZ (cat) amyE:: $P_{h s}-$ oat $A^{+}$ & \\
\hline JLH176 & PY79 pyrD :: $P_{\text {sigv }}$-lacZ (cat) amyE:: $P_{h s}-p d a C^{+}$ & \\
\hline JLH121 & PY79 pyrD:: $P_{\text {sigv }}-$ lacZ (cat) amyE:: $P_{\text {sigV }}-$ lac $Z$ (spec) & \\
\hline
\end{tabular}

${ }^{a}$ Unless otherwise noted, all strains are isogenic derivatives of PY79.

${ }^{b}$ This study, unless otherwise noted.

and measurements of the optical density at $600 \mathrm{~nm}\left(\mathrm{OD}_{600}\right)$ were taken using a Tecan F50 (Tecan). The remaining cells were permeabilized by mixing with chloroform and $2 \%$ Sarkosyl $(28,42)$. The permeabilized cells $(100 \mu \mathrm{l})$ were added to 96 -well plates with $10 \mathrm{mg} / \mathrm{ml}$ ortho-nitrophenyl- $\beta$-galactoside (ONPG, $50 \mu \mathrm{l}$; RPI), and the $\mathrm{OD}_{405}$ was measured every $1 \mathrm{~min}$ for $45 \mathrm{~min}$. $\beta$-Galactosidase activity units were determined using the following calculation ( $\mu$ mol of ONP formed $\left.\mathrm{min}^{-1}\right) \times 10^{3} /\left(\mathrm{OD}_{600} \times\right.$ $\mathrm{ml}$ of cell suspension) as previously described (43). Experiments were performed in triplicate. Means and standard deviations are shown.

Determination of MIC. The MIC was determined by diluting overnight cultures 1:100 and growing cells to an $\mathrm{OD}_{600}$ of 1.5 in LB containing $1 \mathrm{mM}$ IPTG. The cultures were corrected to an $\mathrm{OD}_{600}$ of 0.8 and diluted
1:50 in LB containing $1 \mathrm{mM}$ IPTG. The cell mixtures (50 $\mu \mathrm{l})$ were inoculated into $200 \mu \mathrm{l}$ of LB containing $1 \mathrm{mM}$ IPTG with hen egg white lysozyme ranging from $100 \mu \mathrm{g} / \mathrm{ml}$ to $0.10 \mu \mathrm{g} / \mathrm{ml}$ in a round-bottom 96well plate. The cells were grown for $16 \mathrm{~h}$ at $37^{\circ} \mathrm{C}$. Growth was defined as an $\mathrm{OD}_{600}$ greater than 0.05 . All assays were performed in triplicate on the same day, and each MIC determination was performed on three different days.

Expression of $6 \times$ His-tagged RsiV. Overnight cultures of E. coli BL21 $\lambda$ DE3 containing pKBW202 (pDEST17-6×His-rsi $V^{59-285}$ ) were grown at $30^{\circ} \mathrm{C}$ in $\mathrm{LB}$ with $100 \mu \mathrm{g} / \mathrm{ml}$ ampicillin. The following day, cell cultures were diluted 1:100 into $500 \mathrm{ml}$ of fresh $\mathrm{LB}$ with ampicillin in 2-liter baffled flasks and incubated at $30^{\circ} \mathrm{C}$ until reaching an $\mathrm{OD}_{600}$ of 0.5 
A.

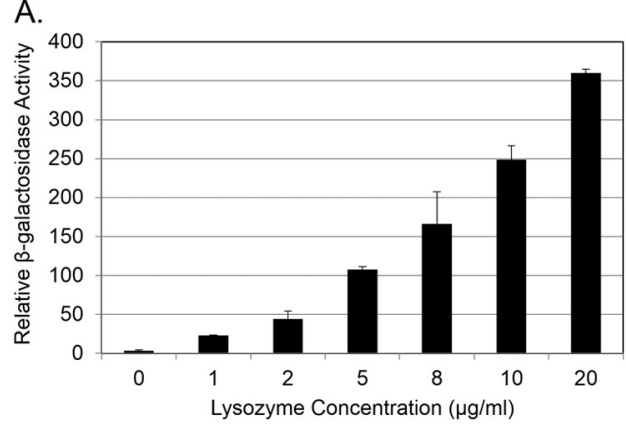

B.

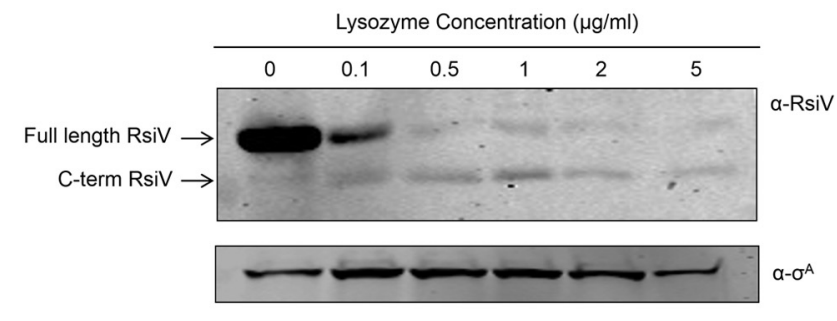

FIG 1 RsiV degradation and $\sigma^{\mathrm{V}}$ induction occur in a lysozyme concentration-dependent manner. (A) B. subtilis with transcriptional fusion $\mathrm{P}_{\text {sigV }}$-lac $Z$ (CDE1546) was grown overnight at $30^{\circ} \mathrm{C}$ and spotted $(20 \mu \mathrm{l})$ in triplicate on $\mathrm{LB}$ agar plates with various concentrations of lysozyme $(0,2,5,10$, or $20 \mu \mathrm{g} / \mathrm{ml})$. Plates were incubated at $37^{\circ} \mathrm{C}$ for $6 \mathrm{~h}$. Cells were collected and resuspended in Z buffer. $\beta$-Galactosidase activity was calculated as described in Materials and Methods. (B) B. subtilis expressing an IPTG-inducible rsiV in a $\Delta s i g V \Delta r s i V$ mutant (JLH402 $\Delta s i g V \Delta r s i V:: k a n \mathrm{P}_{h s}-r s i V^{+}$) was grown to mid-log phase and then incubated with increasing concentrations of hen egg white lysozyme $(0,0.1,0.5,1,2$, and $5 \mu \mathrm{g} / \mathrm{ml})$ for 10 min. The immunoblot was probed with antibodies against the extracellular domain of $\operatorname{RsiV}(\alpha-\operatorname{RsiV})$ and the cytoplasmic protein $\sigma^{\mathrm{A}}\left(\alpha-\sigma^{\mathrm{A}}\right)$.

to 0.6 . IPTG was added to a final concentration of $1 \mathrm{mM}$ to induce protein production, and the cultures incubated for an additional $4 \mathrm{~h}$. At that time, the cells were chilled on ice and collected by centrifugation at 5,000 $\times \mathrm{g}$. The cell pellets were stored at $-80^{\circ} \mathrm{C}$ until time for purification.

Purification of $6 \times$ His-tagged RsiV. Cell pellets were thawed on ice and resuspended in $5 \mathrm{ml}$ lysis buffer $(50 \mathrm{mM}$ sodium phosphate, $250 \mathrm{mM}$ $\mathrm{NaCl}, 10 \mathrm{mM}$ imidazole, pH 8.0) per $500 \mathrm{ml}$ of initial culture volume. The cells were lysed by passaging through a Microfluidics LV1 high-shear microfluidizer (Newton, MA) twice. Lysate was centrifuged at $15,000 \times g$ for $30 \mathrm{~min}$ at $4^{\circ} \mathrm{C}$ to pellet cellular debris. The cleared lysate was applied to a nickel affinity column to bind $6 \times$ His-tagged protein (Qiagen). The column was washed with 10 column volumes of wash buffer $(50 \mathrm{mM}$ sodium phosphate, $250 \mathrm{mM} \mathrm{NaCl}, 20 \mathrm{mM}$ imidazole, $\mathrm{pH}$ 8.0). Protein was eluted with elution buffer $(50 \mathrm{mM}$ sodium phosphate, $250 \mathrm{mM} \mathrm{NaCl}, 250 \mathrm{mM}$ imidazole, $\mathrm{pH}$ 8.0) and collected in 0.5-ml fractions. Samples from each fraction were analyzed by SDS-PAGE, and elution fractions containing the desired protein were combined. The combined fractions were then dialyzed into lysis buffer to remove the excess imidazole. The protein was further purified with a GE Healthcare ÄKTA fast protein liquid chromatography (FPLC) system (GE Healthcare Sciences, Pittsburg, PA) using a HisTrap HP nickel affinity column. The fractions containing $6 \times$ His-RsiV $^{59-285}$ were again combined, dialyzed into a storage buffer (25 mM Tris, $200 \mathrm{mM} \mathrm{NaCl}, 5 \%$ glycerol, $\mathrm{pH} 8.0$ ), and frozen at $-80^{\circ} \mathrm{C}$ until use.

Production of anti-RsiV polyclonal antibodies. Purified $6 \times$ His$\mathrm{RsiV}^{59-285}$ protein was sent for production of polyclonal antibodies in New Zealand White rabbits (ProSci Inc., San Diego, CA). Serum from the final bleed showed high specificity in the detection of RsiV at dilutions of $1: 10,000$.

Immunoblot analysis. For immunoblot analysis, cultures were grown overnight at $30^{\circ} \mathrm{C}$ and subcultured at a dilution of $1: 50$ into $5 \mathrm{ml} \mathrm{LB}$ broth supplemented with $1 \mathrm{mM}$ IPTG or $0.5 \mathrm{mM}$ IPTG (GFP constructs). Cells were grown at $37^{\circ} \mathrm{C}$ with rotation to mid-log phase $\left(\mathrm{OD}_{600}\right.$ of 0.8 to 1.0$)$ and were left untreated as a control or were treated for $10 \mathrm{~min}$ with hen egg white lysozyme ( $2 \mu \mathrm{g} / \mathrm{ml}$ unless otherwise noted). The cells $(1.5 \mathrm{ml})$ were then pelleted by centrifugation, resuspended in $100 \mu \mathrm{l}$ of $2 \times$ sample buffer (65.8 mM Tris-HCl, pH 6.8, 2.1\% SDS, 26.3\% [wt/vol] glycerol, $0.01 \%$ bromophenol blue, and $5 \% \beta$-mercaptoethanol), and lysed by sonication. Samples were electrophoresed on a $15 \%$ SDS-polyacrylamide gel (Bio$\mathrm{Rad})$. The proteins were then blotted onto nitrocellulose and incubated with one of the following primary antibodies: anti-RsiV $(1: 10,000)$, antiGFP $(1: 10,000)$, or anti- $\sigma^{\mathrm{A}}(1: 15,000)$ antibodies. The primary antibody was detected by incubation with goat anti-rabbit IRDye 800CW antibody (1:10,000, LiCor), and the immunoblots were imaged on an Odyssey CLx (LiCor).
Transposon mutagenesis of a strain carrying a $\mathbf{P}_{\text {sigV }}$-lac $Z$ reporter fusion. Transposon mutagenesis was performed to identify mutants which blocked lysozyme induction of $\mathrm{P}_{\text {sigV }}$-lac $Z$. The transposon TnHyJump (44) was used to mutagenize JLH121, which contains two copies of $\mathrm{P}_{\text {sigV }}$-lac $Z$ (amyE:: $\mathrm{P}_{\text {sigV }}$-lacZ pyrD:: $\mathrm{P}_{\text {sigV }}$-lacZ), in order to avoid isolating simple lac $Z$ null mutants. pEP20 (44) was transformed into JLH121, and cells were grown at $30^{\circ} \mathrm{C}$ overnight. The strains were subcultured 1:100 into $2 \mathrm{ml} \mathrm{LB}$ plus MLS, grown at $30^{\circ} \mathrm{C}$ for $3 \mathrm{~h}$, shifted to $37^{\circ} \mathrm{C}$ for $4 \mathrm{~h}$, and then frozen at $-80^{\circ} \mathrm{C}$ after the addition of $400 \mu 150 \%$ glycerol to create pools of cells. Each pool was serially diluted, plated for single colonies on LB plus kanamycin, and grown overnight. The resulting colonies were replicate plated to LB plus X-Gal $(100 \mu \mathrm{g} / \mathrm{ml})$, IPTG $(1 \mathrm{mM})$, and lysozyme $(20 \mu \mathrm{g} / \mathrm{ml})$ and incubated at $37^{\circ} \mathrm{C}$ for $6 \mathrm{~h}$. Cells which were unable to induce the expression of $\mathrm{P}_{\text {sigV }}$-lac $Z$ were isolated, and the location of the mutation determined by sequencing as previously described (44).

\section{RESULTS}

RsiV is degraded in response to lysozyme stress. We previously demonstrated that $B$. subtilis $\sigma^{\mathrm{V}}$ activity was induced in the presence of lysozyme (28). The activity of $\sigma^{\mathrm{V}}$ is inhibited by a membrane-tethered anti- $\sigma$ factor, RsiV (29). Several ECF $\sigma$ factors are activated by proteolytic destruction by anti- $\sigma$ factors $(17,21,45)$. To better understand the activation of $\sigma^{\mathrm{V}}$, we sought to examine the effect of increasing lysozyme concentrations on a reporter of $\sigma^{\mathrm{V}}$ activity $\left(\mathrm{P}_{\text {sigV }}\right.$-lac $\left.\mathrm{Z}\right)$ and on the stability of the anti- $\sigma$ factor RsiV. We first determined the effect of increasing concentrations of lysozyme on the expression of a $\mathrm{P}_{\text {sigV }}$-lacZ transcriptional reporter. We found that increasing concentrations of lysozyme resulted in increased expression of the $\mathrm{P}_{\text {sigV }}$-lac $Z$ reporter (Fig. 1A).

The sigV and $r s i V$ genes are encoded in an operon, and the expression of this operon is $\sigma^{\mathrm{V}}$ dependent (29). Therefore, to determine the effects of lysozyme stress on RsiV stability, we sought to uncouple $r s i V$ expression from $\sigma^{\mathrm{V}}$ activity. We constructed a strain which lacked the chromosomal copy of $\operatorname{sig} V$ and $r s i V$ and expressed $r s i V^{+}$from an IPTG-inducible promoter (JLH402). After growing the cells to mid-log phase, we treated them with increasing concentrations of lysozyme for $10 \mathrm{~min}$. The levels of RsiV were monitored by immunoblotting with polyclonal antibodies that had been raised against the extracellular C-terminal domain of RsiV. We detected a 32-kDa protein in the absence of lysozyme, which corresponds to the size of full-length RsiV (Fig. 1B). We found that at the lowest concentrations of lysozyme $(0.1 \mu \mathrm{g} / \mathrm{ml})$, 


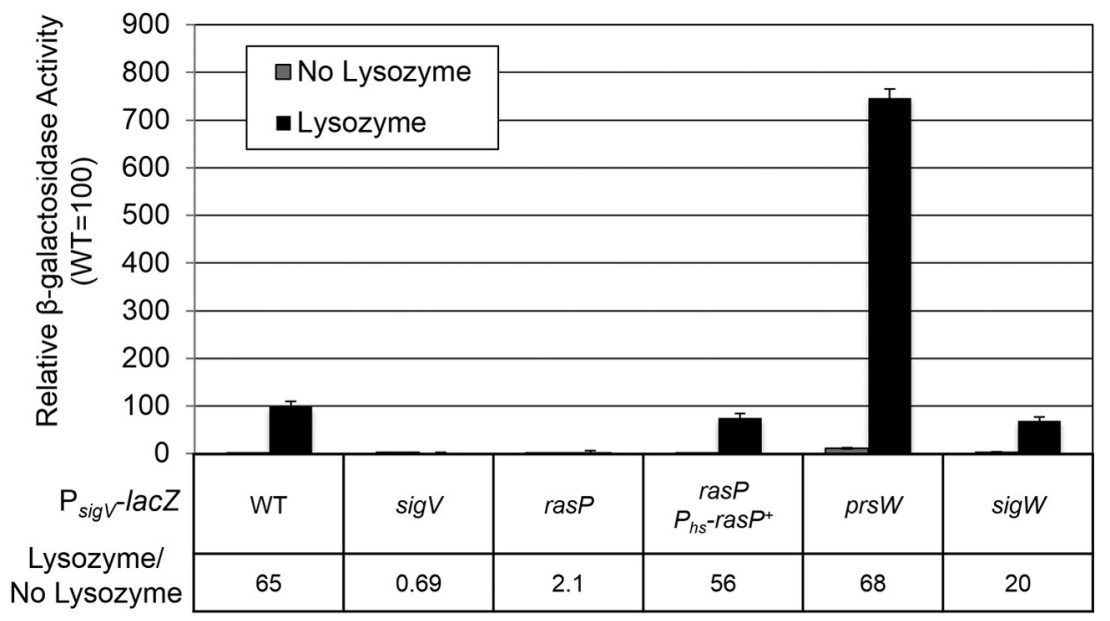

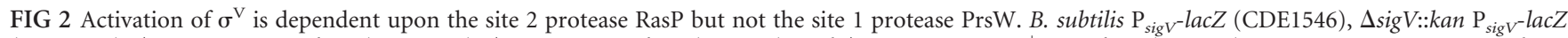
(CDE1547), $\Delta$ prsW::erm $\mathrm{P}_{\text {sigV }}$-lacZ (CDE1549), $\Delta$ rasP::tet $\mathrm{P}_{\text {sigV }}$-lacZ (JLH653), and $\Delta$ rasP::tet $\mathrm{P}_{\text {hs }}$-ras $P^{+} \mathrm{P}_{\text {sigV }}$-lacZ (JLH640) strains were grown overnight at $30^{\circ} \mathrm{C}$ and spotted $(20 \mu \mathrm{l})$ in triplicate on plates containing LB supplemented with IPTG $(1 \mathrm{mM})$ and LB supplemented with IPTG $(1 \mathrm{mM})$ plus lysozyme $(10$ $\mu \mathrm{g} / \mathrm{ml}$ ). Plates were incubated at $37^{\circ} \mathrm{C}$ for $6 \mathrm{~h}$. Cells were collected and resuspended in Z buffer. $\beta$-Galactosidase activity was calculated as described in Materials and Methods. Wild type (WT) induction in the presence of lysozyme was set as 100.

we observed partial loss of full-length RsiV. However, at higher concentrations of lysozyme, $0.5 \mu \mathrm{g} / \mathrm{ml}$ and greater, RsiV was almost completely degraded (Fig. 1B). We found that, as the 32-kDa protein decreased, a smaller product of $\sim 25 \mathrm{kDa}$ appeared (Fig. 1B). This band is presumably the extracellular domain of RsiV alone (Fig. 1B). Decreasing the amount of time cells were incubated with lysozyme to 2 min resulted in similar levels of degradation (data not shown). These data suggest that the $\sigma^{\mathrm{V}}$ anti- $\sigma$ factor RsiV is rapidly degraded following lysozyme exposure and that this degradation is dependent upon the lysozyme concentration.

The site 2 protease RasP is required for $\boldsymbol{\sigma}^{\mathrm{v}}$ activation. In $B$. subtilis, the only anti- $\sigma$ factor known to be degraded by a proteolytic cleavage cascade is RsiW, which controls the activation of $\sigma^{\mathrm{W}}$. After the degradation of RsiW is initiated by PrsW, it is trimmed by an unknown protease and then cleaved by the site 2 protease RasP (17-19). We sought to determine if the site 1 protease PrsW and site 2 protease RasP were required for $\sigma^{\mathrm{V}}$ activity. We examined the effects of $\operatorname{prs} W$ and $r a s P$ null mutations on $\sigma^{\mathrm{V}}$ activity in response to lysozyme by monitoring the $\beta$-galactosidase activity from a $\mathrm{P}_{\text {sigV }}$-lac $Z$ reporter. In wild-type cells, $\mathrm{P}_{\text {sigv }}$-lac $Z$ expression is induced $\sim 65$-fold in the presence of lysozyme (Fig. 2). As expected, in the absence of $\sigma^{\mathrm{V}}, \mathrm{P}_{\text {sigV }}$ is not induced in response to lysozyme (Fig. 2). In the ras $P$ mutant background, $\mathrm{P}_{\text {sigV }}$ induction is limited to low basal levels even in the presence of lysozyme (Fig. 2). The defect in $\mathrm{P}_{\text {sig }}$-lacZ expression in the ras $P$ mutant could be complemented by expressing ras $P^{+}$from an ectopic locus (Fig. 2), suggesting that RasP is required for $\sigma^{\mathrm{V}}$ activation. In contrast, the expression of $\mathrm{P}_{\text {sigV }}$-lac $Z$ was induced $\sim 68$-fold in response to lysozyme in the prs $W$ mutant (Fig. 2), which suggests that PrsW is not required for $\sigma^{\mathrm{V}}$ activation. It appears that the expression of $\mathrm{P}_{\text {sigv }}$-lac $Z$ is induced to a much greater level in the prs $W$ mutant than in the wild type when lysozyme is present (Fig. 2). However, the basal level of $\mathrm{P}_{\text {sigv }}$-lac $Z$ is also significantly higher in the $p r s W$ mutant, and thus, the fold induction of $\mathrm{P}_{\text {sig }}$-lac $Z$ in both the wild type and the prs $W$ mutants is $\sim 65$-fold (Fig. 2). We found that a sigW mutation does not result in an increase similar to that in the prs $W$ mutant (Fig. 2). This suggests that the effect of the prsW mutation is not due to an inability to activate $\sigma^{\mathrm{W}}$. It was recently demonstrated that PrsW altered the levels of several membrane proteins in a $\sigma^{\mathrm{W}}$-independent manner, suggesting that PrsW has additional roles in the cell (46). Our results do demonstrate that RasP is required for the lysozyme induction of $\sigma^{\mathrm{V}}$ activity and that PrsW is dispensable.

RasP is required for site 2 cleavage of RsiV. Since RasP is required for $\sigma^{\mathrm{V}}$ activity and is a known site 2 protease for other ECF anti- $\sigma$ factors, we tested the effects of a rasP mutant on RsiV degradation. Cells expressing $r s i V$ from an IPTG-inducible promoter were grown to mid-log phase and were left untreated or treated with lysozyme $(2 \mu \mathrm{g} / \mathrm{ml})$ for $10 \mathrm{~min}$. The state of RsiV was probed using anti-RsiV antibodies which detect only the C-terminal 230 amino acids of RsiV. As expected, RsiV was cleaved to near completion in both the wild-type and prsW mutant strain (Fig. 3A). Similarly, we found that a ras $P$ mutation did not inhibit cleavage of RsiV in the presence of lysozyme (Fig. 3A). This is not surprising, since the $\mathrm{C}$-terminal product would be the result of successful site 1 cleavage and our antibodies were raised against the C-terminal portion of RsiV.

RasP is known to perform site 2 cleavage of RsiW (47). To determine if RasP is required for site 2 cleavage of RsiV, we constructed a strain producing an N-terminal GFP-RsiV ${ }^{+}$fusion protein which localizes to the cell membrane (see Fig. S2 in the supplemental material). Cells producing GFP-RsiV ${ }^{+}$were treated as described above and then probed with either anti-RsiV or antiGFP antibodies. When using anti-RsiV antibodies to follow GFP$\mathrm{RsiV}^{+}$degradation, we found that GFP-RsiV ${ }^{+}$was degraded in response to lysozyme similarly to wild-type RsiV (Fig. 3B). Consistent with previous results, neither the absence of PrsW nor of RasP altered the degradation of RsiV (Fig. 3B). However, when the same samples were probed using anti-GFP antibodies to detect the $\mathrm{N}$-terminal portion of the GFP-RsiV fusion protein, we were able to detect further cleavage events (Fig. 3C). In the presence of lysozyme, a faint band corresponding to a truncated form of GFP$\mathrm{RsiV}^{+}$could be observed in both wild-type and prsW mutant cells 
A.

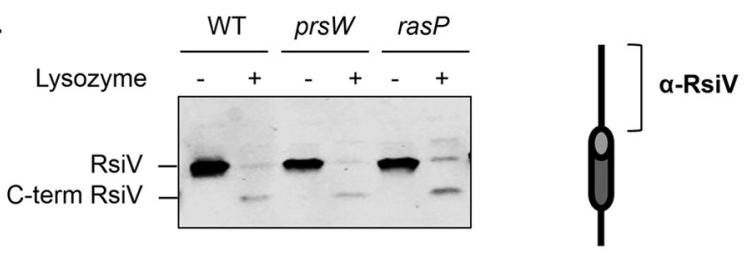

B.
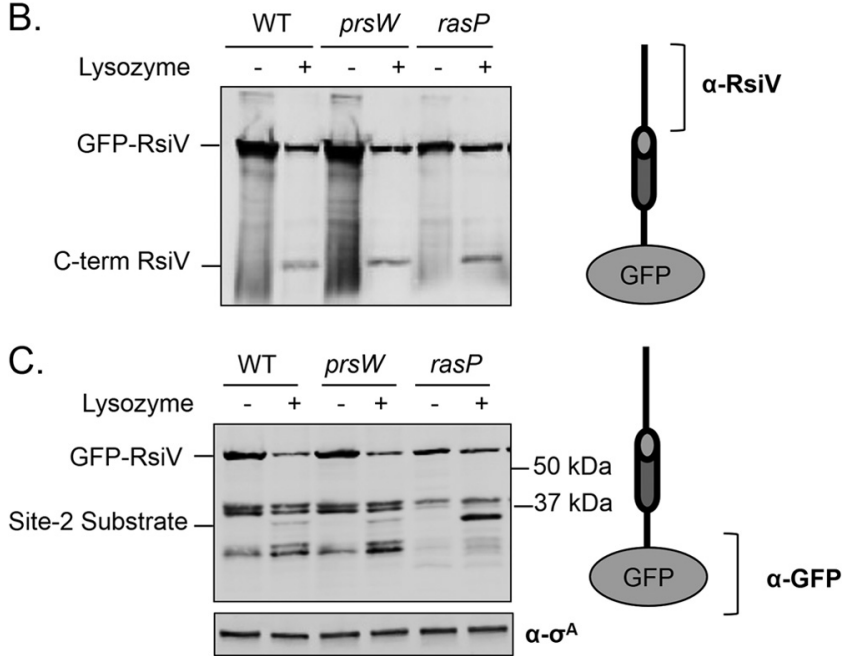

FIG 3 RsiV degradation is dependent upon the site 2 protease RasP. B. subtilis containing an IPTG-inducible copy of $r s i V^{+}$(JLH402) or $g f p-r s i V^{+}$(JLH453) was subcultured 1:100 into LB supplemented with IPTG $(1 \mathrm{mM}$ or $0.5 \mathrm{mM}$, respectively). Strains with a site 1 prsW mutation (JLH415 and JLH465) were grown in the same manner. Strains with a site 2 rasP mutation (JLH416 and JLH466) were subcultured 1:50 but otherwise grown similarly. At mid-log phase, cultures were incubated for 10 min without $(-)$ or with $(+)$ lysozyme $(2 \mu \mathrm{g} / \mathrm{ml})$ at $37^{\circ} \mathrm{C}$. The immunoblot was probed with anti-RsiV antibodies (A and B) or anti-GFP antibodies (C).

(Fig. 3C). In the absence of RasP, we observed an increase in this truncated product of GFP-RsiV only when the cells had been treated with lysozyme (Fig. 3C). This suggests that RasP is required for site 2 cleavage of RsiV.

PT inhibits degradation of GFP-RsiV at site 2. Although $B$. subtilis RasP is not essential for growth, a ras $P$ mutation has pleiotropic effects. Mutants of rasP grow more slowly in liquid, are not competent, cannot activate $\sigma^{\mathrm{W}}$, have cell division defects, and have decreased long-term survival $(26,47,48)$. Since the deletion of ras $P$ affects several other cellular processes, we sought to temporarily inhibit RasP function by using an inhibitor to avoid the secondary effects due to long-term growth without RasP. The site 2 intramembrane metalloproteases are dependent upon the coordination of zinc for enzymatic activity (49). The chelator 1,10phenanthroline (PT) inhibits site 2 protease function by chelating the zinc molecule (49). Using the GFP-RsiV ${ }^{+}$construct to follow RsiV degradation, cells were grown to mid-log phase and then treated for $30 \mathrm{~min}$ with increasing concentrations of PT. The cells were then incubated with lysozyme $(2 \mu \mathrm{g} / \mathrm{ml})$ for $10 \mathrm{~min}$. At the highest concentration of PT, a truncated product of GFP-RsiV accumulates that is the same size as the product that accumulates in the rasP mutant (Fig. 4). As a control, we also compared the effects of PT on the degradation of GFP-RsiV in a rasP mutant. We did not detect any further accumulation of the site 1 product in the ras $P$ mutant even with the highest levels of $\mathrm{PT}$. This suggests that the effect of PT is likely via inhibition of the site 2 protease RasP. This provides further evidence that RasP is required for site 2 cleavage of RsiV and indicates that, like other site 2 proteases, zinc is likely necessary for RasP function.

RasP constitutively degrades an RsiV intermediate. In other systems, site 2 cleavage is preceded by and dependent upon site 1 cleavage to remove the extracellular domain of the target anti- $\sigma$ factor $(17,20,48,50)$. To mimic site 1 cleavage of RsiV, we constructed a strain producing GFP-RsiV ${ }^{1-60}$, which lacks the extracellular domain. Wild-type cells expressing full-length GFP$\mathrm{RsiV}^{+}$showed lysozyme-dependent degradation of RsiV (Fig. 5). In the absence of RasP, full-length GFP-RsiV ${ }^{+}$develops a truncated form of GFP-RsiV only in the presence of lysozyme (Fig. 5). When we examined wild-type cells producing GFP-RsiV ${ }^{1-60}$, lacking the extracellular domain, the fusion protein was undetectable in the presence and absence of lysozyme (Fig. 5). Note that free GFP accumulates in all strains producing the $\mathrm{RsiV}^{1-60}$ truncation, suggesting that the truncated fusion protein is inherently unstable and may be degraded by other proteases as well (Fig. 5). However, in the rasP mutant, we observed accumulation of GFP-RsiV ${ }^{1-60}$ regardless of whether cells had been exposed to lysozyme or not (Fig. 5). This suggests that, similar to other ECF $\sigma$ factors, which are regulated by intramembrane proteases, RasP cleavage of RsiV occurs after site 1 cleavage and is constitutive once site 1 processing has occurred.

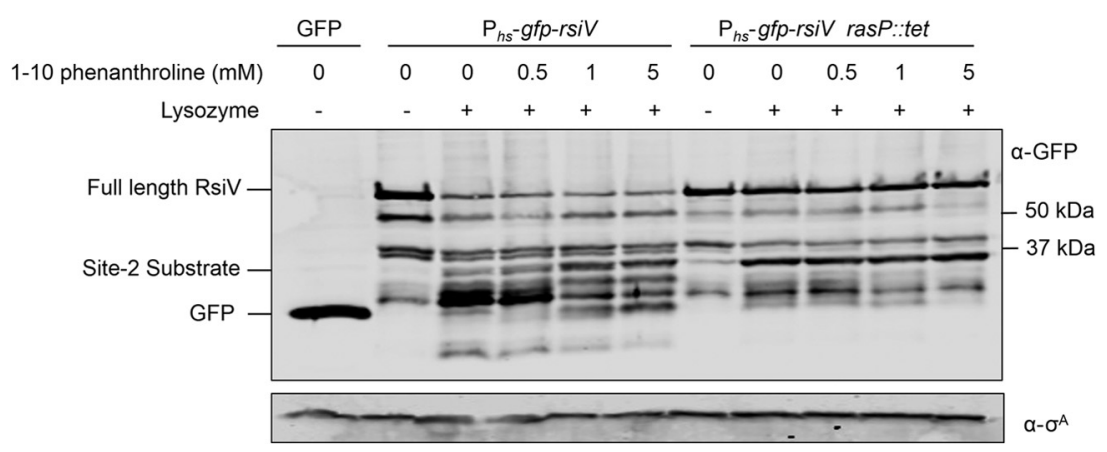

FIG 4 1,10-phenanthroline inhibits site 1 protease cleavage. B. subtilis cells of $\mathrm{P}_{h s}-g f p-r s i V$ (JLH453) and $\mathrm{P}_{h s}-g f p-r s i V \Delta r a s P:: c a t$ (JLH466) strains were grown overnight and then subcultured 1:100 (JLH453) or 1:50 (JLH466) into $5 \mathrm{ml} \mathrm{LB}$ supplemented with IPTG (0.5 mM). When cultures reached mid-log phase, samples were treated with increasing concentrations of 1,10 -phenanthroline $(0,0.5,1$, and $5 \mathrm{mM})$ for $30 \mathrm{~min}$ and then treated $(+)$ with lysozyme $(2 \mu \mathrm{g} / \mathrm{ml})$ for $10 \mathrm{~min}$ at $37^{\circ} \mathrm{C}$. The immunoblot was probed with anti-GFP antibodies or anti- $\sigma^{\mathrm{A}}$ antibody, which was used as a loading control. 


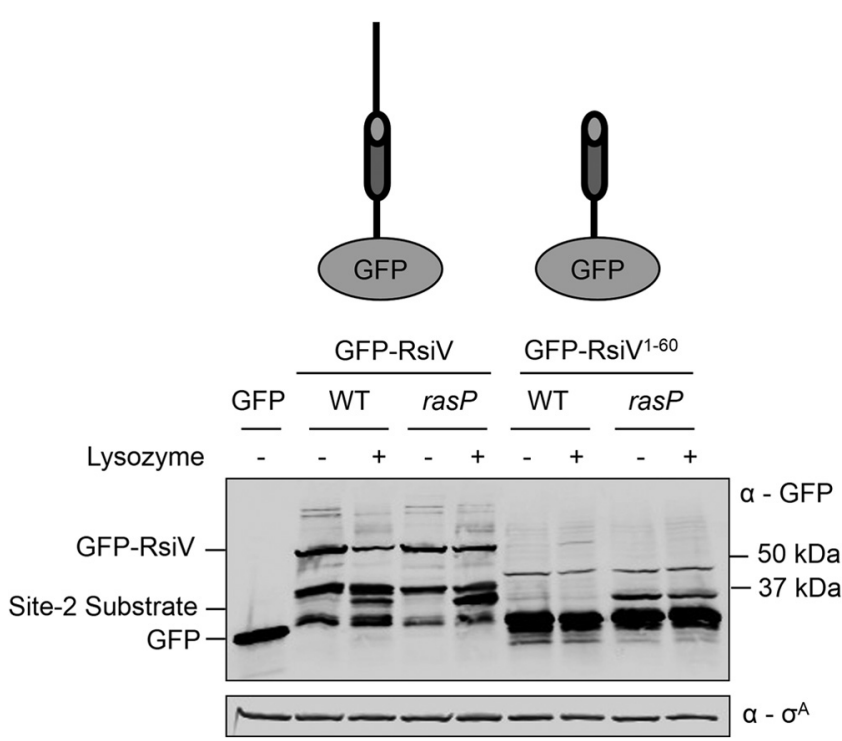

FIG 5 Truncation of RsiV results in constitutive degradation in a RasP-dependent manner. Immunoblot comparing full-length RsiV from $B$. subtilis $\mathrm{P}_{h s}-g f p-r s i V$ (JLH453) and $\mathrm{P}_{h s}$-gfp-rsiV $\Delta$ rasP::cat (JLH466) strains and RsiV without the extracellular domain from $\mathrm{P}_{h s}-g f p-r s i V^{1-60}$ (JLH516) and $\mathrm{P}_{h s}-g f p-$ rsi $V^{1-60} \Delta$ rasP::cat (JLH536) strains. WT strains (JLH453 and JLH516) were subcultured 1:100 into $5 \mathrm{ml} \mathrm{LB}$ supplemented with IPTG $(0.5 \mathrm{mM})$. Strains containing rasP mutations (JLH466 and JLH536) were subcultured 1:50 into 5 $\mathrm{ml}$ LB supplemented with IPTG $(0.5 \mathrm{mM})$. Cultures were grown to mid-log phase and then left untreated $(-)$ or treated $(+)$ with lysozyme $(2 \mu \mathrm{g} / \mathrm{ml})$ for $10 \mathrm{~min}$ at $37^{\circ} \mathrm{C}$. The immunoblot was probed with anti-GFP antibodies or anti- $\sigma^{\mathrm{A}}$ antibody, which was used as a loading control. Cytoplasmic GFP was used as a size control (TPM1263).

Increased lysozyme resistance decreases $\sigma^{\mathrm{v}}$ activation. We performed a transposon screen to identify mutations which altered $\sigma^{\mathrm{V}}$ activation in response to lysozyme. We utilized the transposon TnHyJump, a TnYLB transposon with an outward- facing constitutive promoter, which allowed us to identify both null mutations and insertions which resulted in the overexpression of a gene downstream of the insertion site (44). A strain containing two copies of a $\mathrm{P}_{\text {sigV }}$-lac $Z$ reporter was mutagenized with TnHyJump, and more than 20,000 colonies were screened for either increased or decreased $\mathrm{P}_{\text {sigv-lacZ }}$ expression in the presence of lysozyme. As predicted, we isolated a number of mutations in $\operatorname{sigV}$ which block $\mathrm{P}_{\text {sigV }}$-lac $Z$ expression in the presence of lysozyme (data not shown). We also isolated an insertion immediately upstream from $p d a C(y j e A)$, which encodes a peptidoglycan deacetylase (51). We hypothesized that the constitutive promoter on the transposon led to increased $p d a C$ expression. To determine whether overexpression of $p d a C$ was responsible for the decreased $\mathrm{P}_{\text {sigV }}$-lac $Z$ expression, we constructed a $B$. subtilis strain in which $p d a C$ expression could be induced from an IPTG-inducible promoter. We found that the overexpression of $p d a C$ led to a 2-fold decrease in the expression of $\mathrm{P}_{\text {sigV }}$-lac $Z$ compared to its expression in the wild type (Fig. 6A). This confirmed that increased expression of $p d a C$ caused a decrease in $\mathrm{P}_{\text {sig }}$-lac $Z$ expression.

PdaC deacetylates $N$-acetylmuramic acid, and $p d a C$ null mutants have increased lysozyme sensitivity (51). Therefore, we wanted to determine whether the overexpression of $p d a C$ increased lysozyme resistance. We found that $p d a C$ overexpression causes a 4 -fold increase in lysozyme resistance (Fig. 6B). Since we had shown that increasing concentrations of lysozyme led to increased $\mathrm{P}_{\text {sigV }}$-lacZ expression (Fig. 1), we hypothesized that by increasing resistance to lysozyme, we decreased $\sigma^{\mathrm{V}}$ activation by decreasing the effectiveness of lysozyme for cleaving peptidoglycan. To determine whether this held true for other mechanisms of lysozyme resistance, we also compared the overexpression of oat $A$, which encodes an $O$-acetyltransferase activated by $\sigma^{\mathrm{V}}$ that increases lysozyme resistance $(28,31,32)$. When oatA was overexpressed, lysozyme resistance was increased 2-fold (Fig. 6B). We
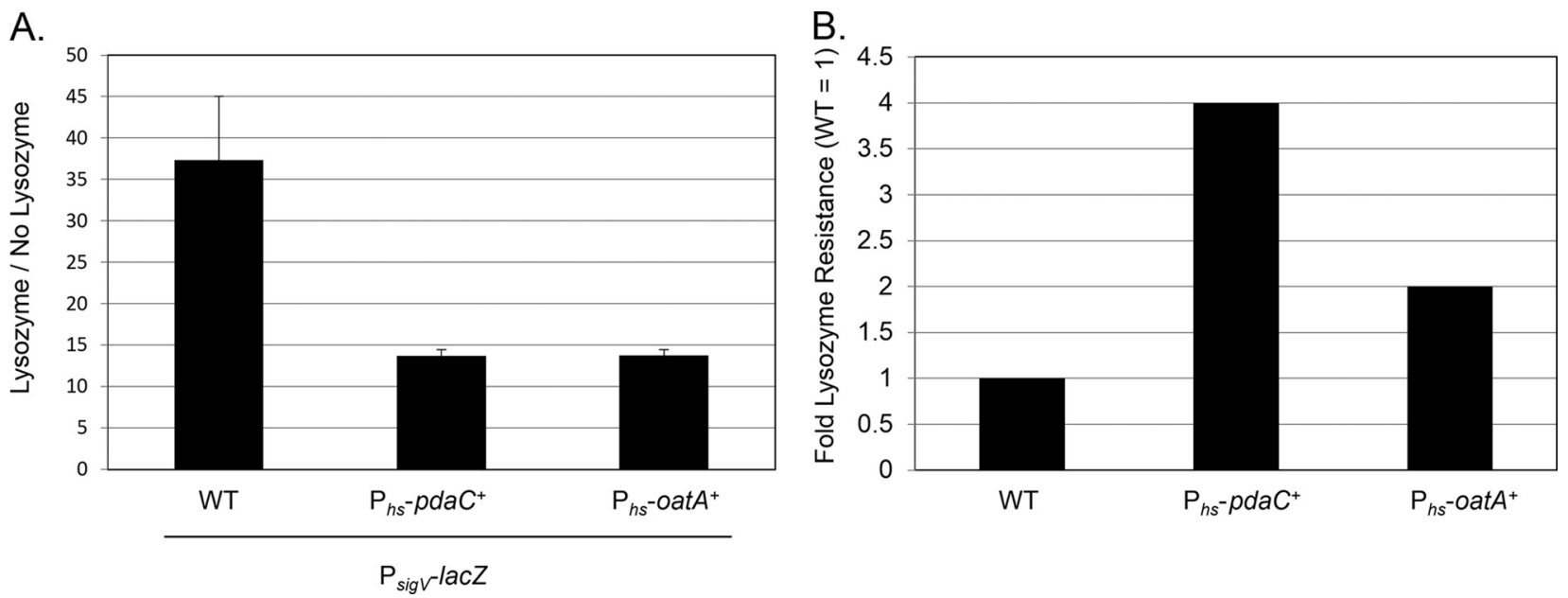

FIG 6 Peptidoglycan modifications decrease $\sigma^{\mathrm{V}}$ activation by increasing lysozyme resistance. (A) B. subtilis wild-type $\left(\mathrm{CDE} 1546 \mathrm{P}_{s i g V}-\right.$ lacZ), $\mathrm{P}_{h s}-p d a C^{+}$(JLH176 $\mathrm{P}_{\text {sigV- }}$-lacZ $\mathrm{P}_{h s}-$ pdaC ${ }^{+}$), and $\mathrm{P}_{h s^{-}}$oatA ${ }^{+}$(JLH345 $\mathrm{P}_{\text {sigV }}$-lac $Z \mathrm{P}_{h s^{-}}$oat ${ }^{+}$) strains were grown overnight at $30^{\circ} \mathrm{C}$ and spotted onto LB plates supplemented with IPTG $(1 \mathrm{mM})$ or LB plates supplemented with IPTG $(1 \mathrm{mM})$ plus hen egg white lysozyme $(10 \mu \mathrm{g} / \mathrm{ml})$. Plates were incubated at $37^{\circ} \mathrm{C}$ for $6 \mathrm{~h}$. Cells were collected and resuspended in Z buffer. $\beta$-Galactosidase activity was calculated as described in Materials and Methods. (B) MICs were determined for wild-type (CDE1546

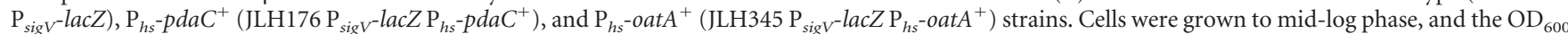
adjusted to 0.8 . The cells were diluted 1:50 into LB supplemented with IPTG $(1 \mathrm{mM})$. Bacteria were added to plates in which lysozyme $(200 \mu \mathrm{g})$ had been serially diluted 2 -fold in a microtiter plate. The plates were incubated overnight at $30^{\circ} \mathrm{C}$, and the $\mathrm{OD}_{600}$ was read. Wells with an $\mathrm{OD}_{600}$ of $<0.05$ were considered to have no growth. The MIC of the WT (PY79) is set to 1. 
found that, similar to the overexpression of $p d a C$, the overexpression of oatA led to a 2 -fold decrease in $\sigma^{\mathrm{V}}$ activation (Fig. 6A). This suggests that the activation of $\sigma^{\mathrm{V}}$ decreases as lysozyme resistance increases.

\section{DISCUSSION}

Here, we have demonstrated that RsiV, the anti- $\sigma$ factor which inhibits $\sigma^{\mathrm{V}}$, is degraded in response to lysozyme stress. Furthermore, our data show that this degradation requires the site 2 protease RasP but not the site 1 protease PrsW. Our data indicate that the activation of $\sigma^{\mathrm{V}}$ requires at least two proteases to degrade RsiV. This is similar to other ECF $\sigma$ factors that are activated by RIP, including $\sigma^{\mathrm{E}}$ from E. coli and $\sigma^{\mathrm{W}}$ from B. subtilis (52). Based on the similarity to analogous systems, we hypothesize that cytosolic proteases are required for degrading the cytoplasmic portion of RsiV after RasP cleavage (17, 20, 53, 54). Using antibodies specific to the C-terminal extracellular domain of RsiV or GFP antibodies and an N-terminal GFP-RsiV fusion protein, we found that full-length RsiV is rapidly and almost completely degraded following brief lysozyme exposure. Additionally, the RsiV extracellular domain is still detectible in lysozyme-treated samples. This raises the possibility that the majority of the RsiV extracellular domain is removed in a single step by cleavage at site 1 in $B$. subtilis. This would be more similar to E. coli, where activation of $\sigma^{\mathrm{E}}$ requires a single cleavage event to allow for the site 2 protease to cleave RseA (13). In contrast, $\sigma^{\mathrm{W}}$ activation requires PrsW cleavage and then further processing by an unknown protease(s) before the site 2 protease RasP efficiently recognizes RsiW as a substrate (17).

The site 2 protease RasP is required for $\sigma^{\mathrm{V}}$ activation. Our data indicate that RasP, the site 2 protease for RsiW, is also required for site 2 cleavage of RsiV. In the absence of site 2 cleavage, either through a rasP mutant or by inhibition of RasP activity using a zinc chelator, a truncated form of RsiV accumulates that cannot be degraded. Our data suggest RasP is the site 2 protease, although we cannot rule out the possibility that additional factors may be involved in site 2 processing. In contrast to the site 1 proteases, which appear highly specific for each substrate, it is becoming increasingly clear that the site 2 proteases can recognize a wide range of substrates. In addition to cleaving anti- $\sigma$ factors RsiV and RsiW, RasP also cleaves the cell division protein FtsL (26). Furthermore, it is thought that RasP aids in clearing signal peptides from the cell membrane (27). RsiV and RsiW do not share any homology at the amino acid level; however, both are single-pass transmembrane anti- $\sigma$ factors. Although it is still unclear how site 2 proteases recognize their substrate, one hypothesis is that site 2 proteases sense membrane proteins with helix-destabilizing amino acids rather than recognizing a specific amino acid sequence, which is consistent with the ability of RasP to act on multiple membrane proteins $(26,47)$.

Our work also suggests that RasP activity is constitutive. We constructed a putative site 2 substrate which lacked the extracellular domain of RsiV. This substrate was degraded by RasP even in the absence of lysozyme. Thus, while lysozyme is required to initiate the proteolytic cascade leading to RsiV destruction, lysozyme is not required to induce RasP activity.

Site 1 cleavage is the regulated step in $\sigma^{\mathbf{V}}$ activation. Site 1 cleavage is the rate-limiting step in the activation of both $\sigma^{\mathrm{E}}$ in $E$. coli and $\sigma^{\mathrm{W}}$ in $B$. subtilis $(18,19,50)$. Our data suggest that the activation of $\sigma^{\mathrm{V}}$ is also controlled at the site 1 cleavage step. First, we found that the accumulation of the truncated GFP-RsiV product was only detected in rasP mutants upon treatment with lysozyme (Fig. 3C), suggesting that the degradation of RsiV in response to lysozyme is tightly controlled. Second, when we mimicked the site 1-cleaved RsiV by constructing GFP-RsiV ${ }^{1-60}$, which lacks the extracellular domain, GFP-RsiV ${ }^{1-60}$ was unstable and was degraded even in the absence of lysozyme. However, in the absence of RasP, the truncated GFP-RsiV ${ }^{1-60}$ accumulates. This mimics the putative site 2 substrate buildup observed when rasP mutant cells producing full-length GFP-RsiV ${ }^{+}$are treated with lysozyme (Fig. 3C and 5). Taken together, these data suggest that site 2 cleavage of RsiV by RasP is not regulated by the presence of lysozyme but simply occurs as a consequence of the appearance of the appropriate substrate. This suggests that the regulation of $\sigma^{\mathrm{V}}$ activity, like several other ECF $\sigma$ factors, is controlled at the level of the site 1 cleavage of the anti- $\sigma$ factor RsiV.

The site 1 protease for RsiV is unknown. We tested whether the known B. subtilis site 1 protease, PrsW, which is required for $\sigma^{\mathrm{W}}$ activation, was involved in RsiV degradation. Our data indicate that PrsW, the site 1 protease for RsiW, is not required for site 1 cleavage of RsiV. In the absence of PrsW, both $\mathrm{P}_{\text {sigV }}$ expression and RsiV degradation remain lysozyme inducible. It is interesting to note that the overall level of $\mathrm{P}_{\text {sigv }}$-lacZ expression was greater in the absence of PrsW. The molecular mechanism for this is currently unclear. It was previously reported that $p r s W$ mutation leads to significant changes in the composition and levels of several membrane proteins (46). Some of these differences were due to an inability of the prsW mutant to activate $\sigma^{\mathrm{W}}(46)$. However, Zweers et al. also found that the absence of PrsW had effects on membrane proteins which could not be accounted for by an inability to activate $\sigma^{\mathrm{W}}$, suggesting that PrsW may have substrates in the cell other than RsiW (46). One possible explanation for increased $\mathrm{P}_{\text {sigV }}$ induction in the absence of PrsW is that the levels of the site 1 protease responsible for cleaving RsiV may be increased. However, we were unable to detect an increase in the degradation of RsiV in the absence of lysozyme. In addition, we did not detect an increase of the RsiV site 2 substrate in a prs $W$ rasP double mutant in the absence of lysozyme (data not shown). We also observed that the levels of RsiV appeared lower in the absence of RasP. In addition, it appears that the amount of RsiV site 1 cleavage is also lower in the absence of RasP. We hypothesize that both of these may be linked to the effect the absence of RasP can have on the accumulation of membrane proteins (46).

In an attempt to identify the site 1 protease, we performed multiple variations on a transposon screen to identify mutants which could not respond to lysozyme, and as yet, we have been unable to identify the site 1 protease. It is possible that multiple proteases are able to perform the initial site 1 cleavage of RsiV or that the site 1 protease is essential. However, if the site 1 protease is essential, it must have other roles in the cell, as $\sigma^{\mathrm{V}}$ itself is not essential. It is interesting that the site 1 proteases have been more difficult to identify in several cases, including ECF $\sigma^{\mathrm{L}}, \sigma^{\mathrm{K}}$, and $\sigma^{\mathrm{M}}$ in M. tuberculosis (23). In addition, while PrsW is absolutely required for site 1 cleavage of RsiW, there is another protease(s) that is required to trim RsiW before the site 2 protease RasP can cleave RsiW within the transmembrane domain (17). This protease(s) has not yet been identified. However, our data suggest that cleavage of RsiV at site 1 is the rate limiting step in $\sigma^{\mathrm{V}}$ activation, and thus, identifying the protease(s) required for this processing step is of interest. 
Increased lysozyme resistance decreases $\sigma^{\mathrm{v}}$ activation. Many stress response signal transduction systems detect a specific environmental stress and, in response, induce changes in gene expression to deal with this stress. By increasing the expression of repair mechanisms to correct damage associated with these stresses, cells downregulate the activation of the stress response system (55). The activation of $\sigma^{\mathrm{V}}$ causes an increase in lysozyme resistance through mechanisms that modify the structure of peptidoglycan (OatA) or lipoteichoic acid (Dlt), thus impairing the ability of lysozyme to cause damage and increasing bacterial survival (28, $31,33)$. Our screen for mutants which block $\sigma^{\mathrm{V}}$ activation included an insertion that led to increased $p d a C$ expression and increased lysozyme resistance (51). We found that increased lysozyme resistance when either $p d a C$ (peptidoglycan deacetylase) or oatA (peptidoglycan $O$-acetyltransferase) was overexpressed caused a marked decrease in $\sigma^{\mathrm{V}}$ activation. This suggests that, like other cell stress response systems, $\sigma^{\mathrm{v}}$ is activated and induces genes which can decrease the damage generated by lysozyme, and in response, $\sigma^{\mathrm{V}}$ activity is then decreased.

Activation of $\sigma^{\mathrm{v}}$ in other organisms. The ECF sigma factor $\sigma^{\mathrm{V}}$ has been identified and shown to be lysozyme inducible in two other Gram-positive organisms, C. difficile and E. faecalis $(34,35)$. This suggests that $\sigma^{\mathrm{V}}$ may be important for controlling resistance to lysozyme in a number of Gram-positive bacteria. In the accompanying article, Varahan et al. (57) show that Eep (a protease required for peptide pheromone production) is required for the $\sigma^{\mathrm{V}}$ activation and site 2 processing of $E$. faecalis RsiV in response to lysozyme. It is not currently known whether a site 2 protease is required for the activation of $\sigma^{\mathrm{V}}$ in C. difficile. However, together, these results suggest that the site 2 proteases are probably involved in the activation of $\sigma^{\mathrm{V}}$ in other organisms as well.

\section{ACKNOWLEDGMENTS}

This work was supported by National Institutes of Health grant R01AI087834 from the National Institute of Allergy and Infectious Diseases to C.D.E. and American Heart Association grant 13PRE14650053 to J.L.H.

We thank members of the Ellermeier laboratory for helpful comments and Theresa D. Ho (University of Iowa) for comments on the manuscript.

\section{REFERENCES}

1. Butcher BG, Mascher T, Helmann JD. 2008. Environmental sensing and the role of extracytoplasmic function (ECF) $\sigma$ factors, p 233-261. In ElSharoud WM (ed), Bacterial physiology: a molecular approach. Springer, Berlin, Germany.

2. Staron A, Sofia HJ, Dietrich S, Ulrich LE, Liesegang H, Mascher T. 2009. The third pillar of bacterial signal transduction: classification of the extracytoplasmic function (ECF) sigma factor protein family. Mol. Microbiol. 74:557-581.

3. Lal M, Caplan M. 2011. Regulated intramembrane proteolysis: signaling pathways and biological functions. Physiology (Bethesda) 26:34-44.

4. Ho TD, Ellermeier CD. 2012. Extra cytoplasmic function $\sigma$ factor activation. Curr. Opin. Microbiol. 15:182-188.

5. Ades SE, Connolly LE, Alba BM, Gross CA. 1999. The Escherichia coli sigma(E)-dependent extracytoplasmic stress response is controlled by the regulated proteolysis of an anti-sigma factor. Genes Dev. 13:2449-2461.

6. Alba BM, Zhong HJ, Pelayo JC, Gross CA. 2001. degS (hhoB) is an essential Escherichia coli gene whose indispensable function is to provide sigma (E) activity. Mol. Microbiol. 40:1323-1333.

7. Walsh NP, Alba BM, Bose B, Gross CA, Sauer RT. 2003. OMP peptide signals initiate the envelope-stress response by activating DegS protease via relief of inhibition mediated by its PDZ domain. Cell 113:61-71.

8. Wilken C, Kitzing K, Kurzbauer R, Ehrmann M, Clausen T. 2004. Crystal structure of the DegS stress sensor: how a PDZ domain recognizes misfolded protein and activates a protease. Cell 117:483-494.
9. Alba BM, Gross CA. 2004. Regulation of the Escherichia coli sigmadependent envelope stress response. Mol. Microbiol. 52:613-619.

10. Kanehara K, Ito K, Akiyama Y. 2002. YaeL (EcfE) activates the sigma(E) pathway of stress response through a site-2 cleavage of anti-sigma(E), RseA. Genes Dev. 16:2147-2155.

11. Kanehara K, Ito K, Akiyama Y. 2003. YaeL proteolysis of RseA is controlled by the PDZ domain of YaeL and a Gln-rich region of RseA. EMBO J. 22:6389-6398.

12. Chaba R, Grigorova IL, Flynn JM, Baker TA, Gross CA. 2007. Design principles of the proteolytic cascade governing the sigmaE-mediated envelope stress response in Escherichia coli: keys to graded, buffered, and rapid signal transduction. Genes Dev. 21:124-136.

13. Alba BM, Leeds JA, Onufryk C, Lu CZ, Gross CA. 2002. DegS and YaeL participate sequentially in the cleavage of RseA to activate the sigma(E)dependent extracytoplasmic stress response. Genes Dev. 16:2156-2168.

14. Luo Y, Asai K, Sadaie Y, Helmann JD. 2010. Transcriptomic and phenotypic characterization of a Bacillus subtilis strain without extracytoplasmic function sigma factors. J. Bacteriol. 192:5736-5745.

15. Wiegert T, Homuth G, Versteeg S, Schumann W. 2001. Alkaline shock induces the Bacillus subtilis sigma(W) regulon. Mol. Microbiol. 41:59-71.

16. Cao M, Wang T, Ye R, Helmann JD. 2002. Antibiotics that inhibit cell wall biosynthesis induce expression of the Bacillus subtilis sigma(W) and sigma(M) regulons. Mol. Microbiol. 45:1267-1276.

17. Heinrich J, Hein K, Wiegert T. 2009. Two proteolytic modules are involved in regulated intramembrane proteolysis of Bacillus subtilis RsiW. Mol. Microbiol. 74:1412-1426.

18. Ellermeier CD, Losick R. 2006. Evidence for a novel protease governing regulated intramembrane proteolysis and resistance to antimicrobial peptides in Bacillus subtilis. Genes Dev. 20:1911-1922.

19. Heinrich J, Wiegert T. 2006. YpdC determines site-1 degradation in regulated intramembrane proteolysis of the RsiW anti-sigma factor of Bacillus subtilis. Mol. Microbiol. 62:566-579.

20. Zellmeier S, Schumann W, Wiegert T. 2006. Involvement of Clp protease activity in modulating the Bacillus subtilis sigma(W) stress response. Mol. Microbiol. 61:1569-1582.

21. Li X, Wang B, Feng L, Kang H, Qi Y, Wang J, Shi Y. 2009. Cleavage of RseA by RseP requires a carboxyl-terminal hydrophobic amino acid following DegS cleavage. Proc. Natl. Acad. Sci. U. S. A. 106:14837-14842.

22. Kinch LN, Ginalski K. 2006. Site-2 protease regulated intramembrane proteolysis: sequence homologs suggest an ancient signaling cascade. Protein Sci. 15:84-93.

23. Sklar JG, Makinoshima H, Schneider JS, Glickman MS. 2010. M. tuberculosis intramembrane protease Ripl controls transcription through three anti-sigma factor substrates. Mol. Microbiol. 77:605-617.

24. Chen G, Zhang X. 2010. New insights into S2P signaling cascades: regulation, variation, and conservation. Protein Sci. 19:2015-2030.

25. Zhang K, Shen X, Wu J, Sakaki K, Saunders T, Rutkowski DT, Back SH, Kaufman RJ. 2006. Endoplasmic reticulum stress activates cleavage of CREBH to induce a systemic inflammatory response. Cell 124:587-599.

26. Wadenpohl I, Bramkamp M. 2010. DivIC stabilizes FtsL against RasP cleavage. J. Bacteriol. 192:5260-5263.

27. Saito A, Hizukuri Y, Matsuo E-i, Chiba S, Mori H, Nishimura O, Ito K, Akiyama Y. 2011. Post-liberation cleavage of signal peptides is catalyzed by the site-2 protease (S2P) in bacteria. Proc. Natl. Acad. Sci. U. S. A. 108:13740-13745.

28. Ho TD, Hastie JL, Intile PJ, Ellermeier CD. 2011. The Bacillus subtilis extracytoplasmic function sigma factor $\sigma^{\mathrm{V}}$ is induced by lysozyme and provides resistance to lysozyme. J. Bacteriol. 193:6215-6222.

29. Zellmeier S, Hofmann C, Thomas S, Wiegert T, Schumann W. 2005. Identification of sigma (v)-dependent genes of Bacillus subtilis. FEMS Microbiol. Lett. 253:221-229.

30. Callewaert L, Michiels CW. 2010. Lysozymes in the animal kingdom. J. Biosci. 35:127-160.

31. Guariglia-Oropeza V, Helmann JD. 2011. Bacillus subtilis $\sigma^{\mathrm{V}}$ confers lysozyme resistance by activation of two cell wall modification pathways, peptidoglycan $\mathrm{O}$-acetylation and D-alanylation of teichoic acids. J. Bacteriol. 193:6223-6232.

32. Bernard E, Rolain T, Courtin P, Guillot A, Langella P, Hols P, ChapotChartier MP. 2011. Characterization of $\mathrm{O}$-acetylation of $\mathrm{N}$ acetylglucosamine: a novel structural variation of bacterial peptidoglycan. J. Biol. Chem. 286:23950-23958.

33. Laaberki M-H, Pfeffer J, Clarke AJ, Dworkin J. 2011. O-Acetylation of 
peptidoglycan is required for proper cell separation and S-layer anchoring in Bacillus anthracis. J. Biol. Chem. 286:5278-5288.

34. Ho TD, Ellermeier CD. 2011. PrsW is required for colonization, resistance to antimicrobial peptides, and expression of extracytoplasmic function sigma factors in Clostridium difficile. Infect. Immun. 79:3229-3238.

35. Le Jeune A, Torelli R, Sanguinetti M, Giard JC, Hartke A, Auffray Y, Benachour A. 2010. The extracytoplasmic function sigma factor SigV plays a key role in the original model of lysozyme resistance and virulence of Enterococcus faecalis. PLoS One 5:e9658. doi:10.1371/journal.pone .0009658 .

36. Benachour A, Muller C, Dabrowski-Coton M, Le Breton Y, Giard JC, Rince A, Auffray Y, Hartke A. 2005. The Enterococcus faecalis SigV protein is an extracytoplasmic function sigma factor contributing to survival following heat, acid, and ethanol treatments. J. Bacteriol. 187:10221035.

37. Youngman P, Perkins JB, Losick R. 1984. Construction of a cloning site near one end of Tn917 into which foreign DNA may be inserted without affecting transposition in Bacillus subtilis or expression of the transposonborne erm gene. Plasmid 12:1-9.

38. Wilson GA. 1968. Nutritional factors influencing the development of competence in the Bacillus subtilis transformation system. J. Bacteriol. 95:1439-1449.

39. Pang YY, Schwartz J, Thoendel M, Ackermann LW, Horswill AR, Nauseef WM. 2010. agr-dependent interactions of Staphylococcus aureus USA300 with human polymorphonuclear neutrophils. J. Innate Immun. 2:546-559.

40. Wach A. 1996. PCR-synthesis of marker cassettes with long flanking homology regions for gene disruptions in S. cerevisiae. Yeast 12:259-265.

41. Guerout-Fleury AM, Shazand K, Frandsen N, Stragier P. 1995. Antibiotic-resistance cassettes for Bacillus subtilis. Gene 167:335-336.

42. Griffith KL, Wolf RE. 2002. Measuring beta-galactosidase activity in bacteria: cell growth, permeabilization, and enzyme assays in 96-well arrays. Biochem. Biophys. Res. Commun. 290:397-402.

43. Slauch JM, Silhavy TJ. 1991. cis-acting ompF mutations that result in OmpR-dependent constitutive expression. J. Bacteriol. 173:4039-4048.

44. Pozsgai ER, Blair KM, Kearns DB. 2012. Modified mariner transposons for random inducible-expression insertions and transcriptional reporter fusion insertions in Bacillus subtilis. Appl. Environ. Microbiol. 78:778785.

45. Kazmierczak MJ, Wiedmann M, Boor KJ. 2005. Alternative sigma fac- tors and their roles in bacterial virulence. Microbiol. Mol. Biol. Rev. 69: 527-543.

46. Zweers JC, Wiegert T, van Dijl JM. 2009. Stress-responsive systems set specific limits to the overproduction of membrane proteins in Bacillus subtilis. Appl. Environ. Microbiol. 75:7356-7364.

47. Schobel S, Zellmeier S, Schumann W, Wiegert T. 2004. The Bacillus subtilis sigma(W) anti-sigma factor RsiW is degraded by intramembrane proteolysis through YluC. Mol. Microbiol. 52:1091-1105.

48. Heinrich J, Lunden T, Kontinen VP, Wiegert T. 2008. The Bacillus subtilis $\mathrm{ABC}$ transporter EcsAB influences intramembrane proteolysis through RasP. Microbiology 154:1989-1997.

49. Feng L, Yan H, Wu Z, Yan N, Wang Z, Jeffrey PD, Shi Y. 2007. Structure of a site-2 protease family intramembrane metalloprotease. Science 318:1608-1612.

50. Grigorova IL, Chaba R, Zhong HJ, Alba BM, Rhodius V, Herman C, Gross CA. 2004. Fine-tuning of the Escherichia coli sigmaE envelope stress response relies on multiple mechanisms to inhibit signal-independent proteolysis of the transmembrane anti-sigma factor, RseA. Genes Dev. 18:2686-2697.

51. Kobayashi K, Sudiarta IP, Kodama T, Fukushima T, Ara K, Ozaki K, Sekiguchi J. 2012. Identification and characterization of a novel polysaccharide deacetylase C (PdaC) from Bacillus subtilis. J. Biol. Chem. 287: 9765-9776.

52. Heinrich J, Wiegert T. 2009. Regulated intramembrane proteolysis in the control of extracytoplasmic function sigma factors. Res. Microbiol. 160: $696-703$.

53. Flynn JM, Neher SB, Kim YI, Sauer RT, Baker TA. 2003. Proteomic discovery of cellular substrates of the ClpXP protease reveals five classes of ClpX-recognition signals. Mol. Cell 11:671-683.

54. Flynn JM, Levchenko I, Sauer RT, Baker TA. 2004. Modulating substrate choice: the SspB adaptor delivers a regulator of the extracytoplasmic-stress response to the AAA + protease ClpXP for degradation. Genes Dev. 18: 2292-2301.

55. Hayden JD, Ades SE. 2008. The extracytoplasmic stress factor, sigmaE, is required to maintain cell envelope integrity in Escherichia coli. PLoS One 3:e1573. doi:10.1371/journal.pone.0001573.

56. Ben-Yehuda S, Rudner DZ, Losick R. 2003. RacA, a bacterial protein that anchors chromosomes to the cell poles. Science 299:532-536.

57. Varahan S, Iyer VS, Moore WT, Hancock LE. 2013. Eep confers lysozyme resistance to Enterococcus faecalis via the activation of the extracytoplasmic function sigma factor SigV. J. Bacteriol. 195:3125-3134. 